\title{
Acholeplasma cavigenitalium sp. nov., Isolated from the Vagina of Guinea Pigs
}

\author{
AURIOL C. HILL \\ Medical Research Council Toxicology Unit, Woodmansterne Road, \\ Carshalton, Surrey SM5 4EF, United Kingdom
}

\begin{abstract}
A mollicutes isolated from a guinea pig vagina was shown to be serologically distinct from previously recognized Mycoplasma and Acholeplasma species. Colonies isolated from 10 different guinea pigs were cloned and examined in detail. These strains were closely related and had the following properties: guanine-pluscytosine content of $36 \mathrm{~mol} \%$, no requirement for sterol, and aerobic growth. Glucose was not metabolized, and arginine and urea were not hydrolyzed. Strain GP3 (= NCTC 11727) is the type strain of a new species, Acholeplasma cavigenitalium.
\end{abstract}

A mollicutes that could not be identified as one of those previously recovered from guinea pigs, i.e., Mycoplasma caviae, M. cavipharyngis, $M$. pulmonis, Acholeplasma granularum, and $A$. laidlawii, was isolated from the vagina of guinea pigs $(12,13,15)$. Strains were recovered from the vagina of 10 guinea pigs from several different colonies. In this paper, I describe the characteristics of these strains in comparison with those of strains of known genera and species and propose that they are members of a new Acholeplasma species.

\section{MATERIALS AND METHODS}

Mycoplasma strains. Mycoplasmas were isolated from the vagina of 10 apparently healthy guinea pigs in several different colonies during routine microbiological screening. Swabs taken from the vagina were rubbed over the surface of an agar culture medium and inoculated into glucose or arginine broth medium $(11,29)$. The inoculated liquid medium was diluted $1 / 10$. One colony isolated from each guinea pig was cloned to produce a pure culture; this was done by filtering a broth culture through a 220 -nm-pore-size membrane filter (Millipore Corp., Bedford, Mass.) by use of a syringe with slight pressure, culturing the filtrate on solid medium, transferring a single resulting colony to another plate, and inoculating the subsequent growth into broth. This entire procedure was repeated four times (27). The clones were designated strains GP3, 158G, 3VU, 148J, 12K, 23K, $75 \mathrm{~K}, 83 \mathrm{~K}, 118 \mathrm{~K}$, and $128 \mathrm{~K}$.

Mycoplasma and Acholeplasma species. Type strains were obtained from the National Collection of Type Cultures, Central Public Health Laboratory, London, England, and from H. Atobe, M. F. Barile, J. M. Bradbury, R. H. Fallon, E. A. Freundt, J. T. Heywood, F. T. W. Jordan, D. E. Jasper, H. Kirchhoff, R. H. Leach, G. J. McGarrity, D. L. Rose, G. Smith, D. Taylor-Robinson, and J. G. Tully.

The following Acholeplasma type strains were used: $A$. axanthum S743, $A$. entomophilum TAC, $A$. equifetale N93, $A$. florum LI, $A$. granularum BTS39, $A$. hippikon C1, $A$. laidlawii PG8, A. modicum PG49, $A$. morum 72-043, $A$. multilocale PN525, $A$. oculi 19L, $A$. parvum H23M, and $A$. seiffertii F7. Ninety-one Mycoplasma type strains were also used.

Medium and growth conditions. The culture medium used was described previously $(11,29)$ and contained thallium acetate and penicillin. The purified agar used in the growth medium was either Ionagar no. 2 (Oxoid Ltd., Basingstoke,
England) or Lab M agar (Lab M, London, England). Depending on their biochemical activities, the mycoplasmas were grown in liquid medium containing $1 \%(\mathrm{wt} / \mathrm{vol})$ glucose (pH 7.8) or in liquid medium containing 0.5 to $1 \%$ (wt/vol) arginine ( $\mathrm{pH} 7.3$ ). The species grown in medium containing arginine were not inhibited by $1 \%$ arginine. Agar cultures were incubated at 35 to $37^{\circ} \mathrm{C}$ either in a humid chamber or under anaerobic conditions in a GasPak system. Liquid cultures were stored at $-70^{\circ} \mathrm{C}$.

Growth requirements and characteristics. The clones were subcultured onto solid medium and incubated under aerobic conditions at 35 to $37^{\circ} \mathrm{C}$. The levels of susceptibility to methylene blue were investigated by adding $0.002 \%$ (wt/vol) methylene blue to the basal solid medium and comparing the growth of inoculated mycoplasmas with the growth of mycoplasmas cultivated on agar medium without methylene blue. Lipolytic activity was tested by inoculating mycoplasmas onto basal medium enriched with $10 \%$ egg yolk emulsion (7). The incubated plates were examined after 3,7 , and 14 days for visual evidence of lipolysis (clearing) or film production.

Absence of reversion. The clones were subcultured by five passages both on solid and in liquid media that contained no microbial inhibitors to determine whether the organisms reverted to bacterial forms. Agar culture colonies of each clone were also treated with Dienes stain to differentiate mycoplasma colonies (which take up the stain more quickly) from bacterial $\mathrm{L}$ forms (30).

Morphological studies. Mycoplasma colonies grown on agar were examined microscopically at a magnification of $\times 100$ after 4,7 , and 14 days of incubation. The colonies were transferred to slides and stained with Giemsa stain $(8,16)$. Liquid cultures were observed by dark-field microscopy, and organisms were stained with Giemsa stain (16). Organisms grown in broth were harvested by centrifugation, and the cell pellet was fixed in $2 \%$ (vol/vol) glutaraldehyde and postfixed in $1 \%$ (wt/vol) osmium tetroxide for $1 \mathrm{~h}$. Thin sections of these preparations were stained with uranyl acetate and then lead citrate and examined by electron microscopy (33).

Filtration studies. Cultures (after $24 \mathrm{~h}$ of incubation) were diluted 1:10 in liquid medium, and the resulting preparations were filtered and refiltered (by use of a syringe with slight pressure) through a series of membrane filters (Millipore) with pore diameters of $220,300,450,650$, and $800 \mathrm{~nm}$. The number of CFU per milliliter in each filtrate was compared with the number in the unfiltered diluted culture. 
Sterol dependence. Single colonies of strains GP3, 3VU, and $158 \mathrm{G}$ were seeded onto serum-free solid medium supplemented with $0.5 \%$ bovine serum albumin, $0.5 \%$ glucose, and $10 \mu \mathrm{g}$ of palmitic acid per ml. Cholesterol, dissolved in Tween 80, was added to yield final concentrations of 20,10 , 5 , and $1 \mu \mathrm{g} / \mathrm{ml}$. Plates without cholesterol were also included $(5,6,24,32)$. In addition, the mycoplasmas were subcultured onto basal agar medium without serum. When growth occurred on any of the serum-free media, single colonies were passaged three times on similar plates to ensure that the growth was not due to carryover of serum from the original culture, which would give misleading results.

The clones were also tested indirectly for sterol dependence by a paper disk inhibition method (9) with either dried disks that originally contained $0.02 \mathrm{ml}$ of a $1.5 \%(\mathrm{wt} / \mathrm{vol})$ ethanolic solution of digitonin (Sigma Chemical Co., St. Louis, Mo.) or wet disks that contained $0.02 \mathrm{ml}$ of a $20 \%$ (wt/vol) aqueous solution of sodium polyanetholesulfonate (Koch-Light Laboratories Ltd., Colnbrook, England) on basal growth medium containing Lab $\mathrm{M}$ agar. The diameters of the zones of growth inhibition were measured in millimeters.

Biochemical activities. The 10 clones were examined for the metabolism of arabinose, arbutin, cellobiose, dulcitol, fructose, galactose, glucose, glycerol, inositol, lactose, maltose, mannitol, mannose, raffinose, rhamnose, salicin, sorbitol, sucrose, trehalose, and xylose; for the hydrolysis of arginine ( 1 and $0.1 \%$ ) and urea; for the reduction of methylene blue, resazurin, tetrazolium, and tellurite; and for phosphatase activity $(1,2,17,26,31,34)$. Positive and negative controls were used for all tests, except for some of the carbohydrates. For all negative results, the viability of the organism was checked.

Erythrocyte tests. The clones were examined for hemolytic activity, hemadsorption, and hemagglutination with guinea pig, human, and sheep erythrocytes $(1,18)$.

Polyacrylamide gel electrophoresis. Electrophoresis was carried out as described by Mouches and Bové (20) with a one-dimensional slab. Centrifuged cell suspensions were dissolved in a solution containing $20 \%$ glycerol, $5 \% 2$-mercaptoethanol, and $3 \%$ sodium dodecyl sulfate in $0.0625 \mathrm{M}$ Tris buffer (pH 6.8). To a $12.5 \%$ acrylamide gel, 10-, 25-, or 50 - $\mu$ l portions of a cell sample were added. Electrophoresis was performed at room temperature for $1 \mathrm{~h}$ at a constant current $(20 \mathrm{~mA})$. The gel was stained with Coomassie blue (Sigma).

DNA base composition. DNAs were extracted from centrifuged broth culture deposits of strains GP3 and $3 \mathrm{VU}$ by the method of Gross-Bellard et al. (10), and the guanine-pluscytosine contents were determined from the buoyant densities of the DNAs in cesium chloride by ultracentrifugation (25). DNA extracted from Escherichia coli and with a known guanine-plus-cytosine content was included as a control.

Serological studies. Antisera were prepared as described by Morton and Roberts (19) and Hill (11). The following three serological methods were used: growth inhibition tests with antiserum-impregnated sterile paper disks (4), metabolic inhibition tests with microtiter plates $(14,22,23,28)$, and immunoperoxidase tests with colonies grown on agar (21). All of the tests were carried out in duplicate. Strains GP3, 3VU, and $158 \mathrm{G}$ were reacted with antisera prepared against the species listed above. Antisera to the three clones were reacted with the previously described Mycoplasma and Acholeplasma species. Antisera to the three clones were reacted with all 10 clones to demonstrate their relationships.

The metabolic inhibition test for strain GP3 and its related strains was adapted in the following way. The strains were grown in broth medium containing $0.004 \%$ (wt/vol) resazurin instead of glucose or arginine and without phenol red. When a change in color was noted (violet to purple-red), the broth was frozen in ampoules at $-70^{\circ} \mathrm{C}$. The test was carried out in the same way as the other metabolic inhibition tests $(22,28)$, except that the diluent was the resazurin broth described above. After incubation at $37^{\circ} \mathrm{C}$, the test was read when a distinct color change was noted for the control well, which contained the organism but no antibody, showing that there was sufficient growth to reduce the resazurin. Resazurin was used in the metabolic inhibition test because strain GP3 did not have the biochemical activity needed for the standard test.

\section{RESULTS AND DISCUSSION}

The strains became visible as colonies upon primary isolation after 1 to 2 weeks of incubation. Growth after several passages was more rapid and became visible after 3 days. No growth was detected under anaerobic conditions upon primary cultivation or after many passages on mycoplasma culture medium. The colonies (Fig. 1) had a typical "fried-egg" appearance. The growth of the strains was not inhibited by methylene blue or on medium without serum. No film was produced on egg yolk agar. None of the strains reverted to a bacterial form when the organisms were subcultured on medium without the bacterial inhibitors thallium acetate and penicillin. The colonies were rapidly stained with Dienes reagent, confirming that they were true mycoplasmas (members of the class Mollicutes) rather than bacterial $\mathrm{L}$ forms (30).

No motility was observed when the strains were examined by dark-field microscopy, and helical forms were not observed. Liquid cultures stained with Giemsa stain contained pleomorphic forms characteristic of mycoplasmas. The ultrastructure of strain GP3 was found to be typical of mycoplasma morphology when thin sections were viewed by electron microscopy (3). The cells were bounded by a single trilaminar membrane and lacked any evidence of cell wall material.

Filtration of a broth culture of strain GP3 showed that reduced numbers of the $4 \times 10^{5} \mathrm{CFU} / \mathrm{ml}$ in the original dilution passed through the 450 -nm-pore-size membrane (1 $\left.\times 10^{4} \mathrm{CFU} / \mathrm{ml}\right)$ and the $300-\mathrm{nm}$-pore-size membrane $\left(2 \times 10^{1}\right.$ $\mathrm{CFU} / \mathrm{ml})$.

Strain GP3 did not require sterol for growth. The strain grew and was passaged on medium that did not contain cholesterol. Strains GP3, 3VU, and 158G were not susceptible to digitonin or sodium polyanetholesulfonate.

The biochemical activities of the 10 strains were identical and are summarized in the species description below. In appropriate tests, all strains were hemolytic for guinea pig, human, and sheep erythrocytes but did not hemadsorb or hemagglutinate these cells.

The guanine-plus-cytosine content of the strains was determined from their DNA buoyant density in cesium chloride to be $36 \mathrm{~mol} \%$.

The serological techniques used revealed similar levels of cross-reactions among the 10 strains. No significant crossreactions were detected with any of the species listed in Materials and Methods.

The strains showed a slight overall variation in their protein patterns that was not due to the amount of protein in each lane, but the patterns were distinct from those of $A$. 


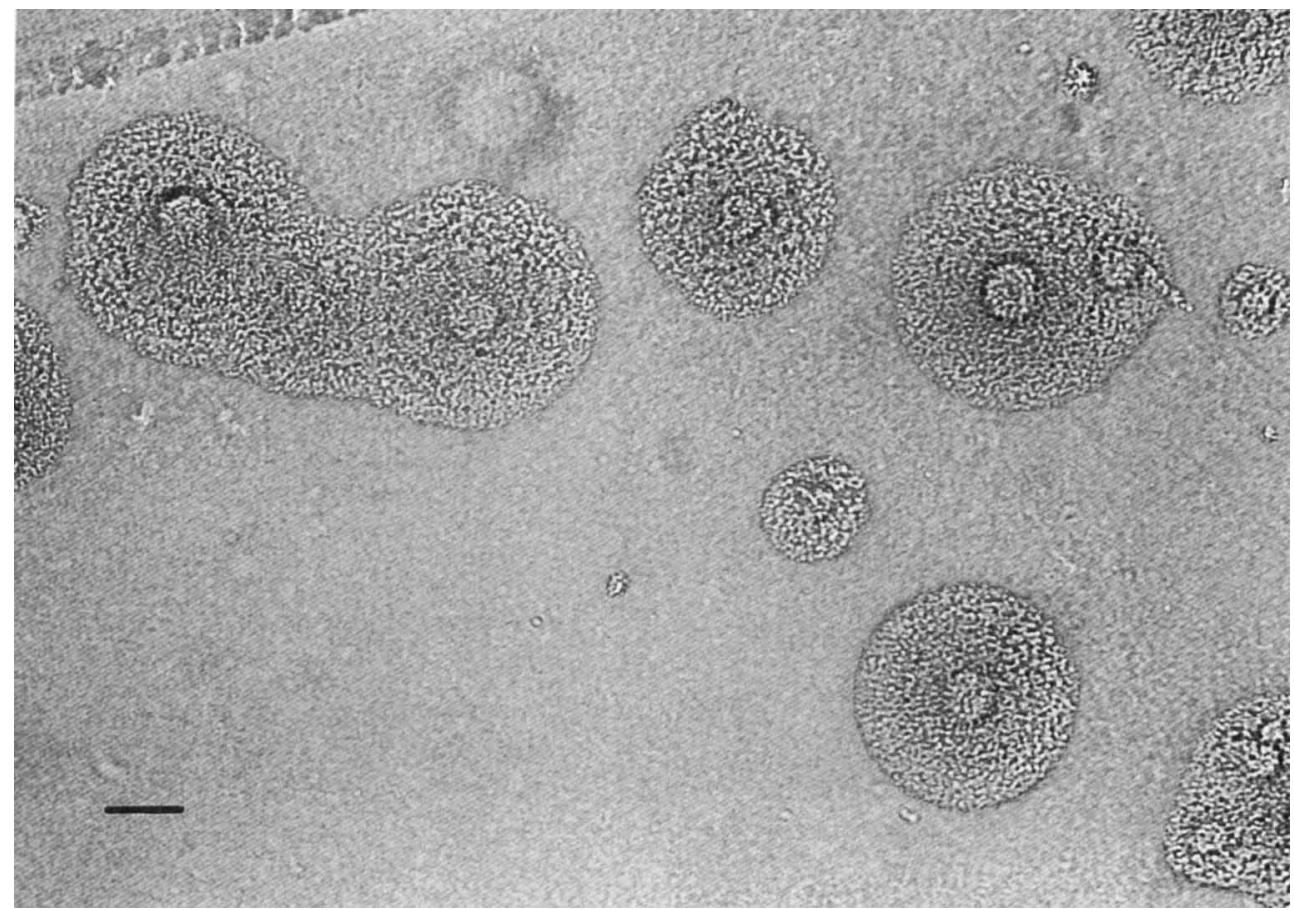

FIG. 1. Colonies of strain GP3 ${ }^{\mathrm{T}}$ grown under aerobic conditions for 7 days on agar medium. Bar, $100 \mu \mathrm{m}$.

laidlawii, $M$. caviae, and $M$. cavipharyngis, other mycoplasmas isolated from guinea pigs.

Strain GP3 belongs to the family Mycoplasmataceae on the basis of its main properties, including absence of cell walls, lack of reversion to bacterial $\mathrm{L}$ forms when grown in antibiotic-free medium, penicillin resistance, filterability, and production of typical morphology on agar. It belongs to the genus Acholeplasma because it is not a strict anaerobe (in contrast to Anaeroplasma spp.), because it is nonhelical (in contrast to Spiroplasma spp.), because it does not require sterol for growth (in contrast to Mycoplasma spp.), and because urease could not be demonstrated (in contrast to Ureaplasma spp.).

The 10 strains belong to the same species, because they had identical biological characteristics and exhibited serological similarities. Because there were no significant crossreactions with any of the previously recognized Mycoplasma or Acholeplasma spp. (listed in Materials and Methods), strain GP3 belongs to a new Acholeplasma species.

This species may be quite common in conventional guinea pig colonies. The lack of isolation is probably due to its relatively slow growth on agar, bacterial contamination of samples taken from guinea pigs, or its inability to metabolize glucose or hydrolyze arginine, resulting in no $\mathrm{pH}$ change in inoculated liquid medium.

Description of Acholeplasma cavigenitalium sp. nov. Acholeplasma cavigenitalium (ca.vi.ge.ni.ta.li.um. L. n. cavia, guinea pig; M. L. pl. n. genitalia, the genitals; M. L. pl. gen. n. cavigenitalium, guinea pig genitals). Pleomorphic cells are bounded by a single membrane. Colonies have a typical fried-egg appearance on agar. Organisms are filterable through 300-nm-pore-size membrane filters and are resistant to penicillin. The organism does not require sterol for growth and is not inhibited by digitonin or sodium polyanetholesulfonate. Optimal growth occurs at 35 to $37^{\circ} \mathrm{C}$ under aerobic conditions. No carbohydrates are metabolized. Arginine and urea are not hydrolyzed. Resazurin is reduced, but methylene blue, tellurite, and tetrazolium are not reduced. Phosphatase is not produced. The organism is serologically distinct from all other Acholeplasma and Mycoplasma species. The DNA base composition is $36 \mathrm{~mol} \%$ guanine plus cytosine. The habitat is the guinea pig vagina. The type strain is strain GP3 (= NCTC 11727).

\section{ACKNOWLEDGMENTS}

I thank C. Colhoun for supplying Fig. 1, G. A. Stalley for estimation of the DNA base composition, and D. Rose and J. G. Tully for some serological comparisons.

\section{REFERENCES}

1. Aluotto, B. B., R. G. Wittler, C. O. Williams, and J. E. Faber. 1970. Standardized bacteriologic techniques for the characterization of Mycoplasma species. Int. J. Syst. Bacteriol. 20:35-58.

2. Barber, T. L., and J. Fabricant. 1971. Identification of Mycoplasmatales: characterization procedures. Appl. Microbiol. 21: 600-605.

3. Boatman, E. S. 1979. Morphology and ultrastructure of the Mycoplasmatales, p. 63-102. In M. F. Barile and S. Razin (ed.), The Mycoplasmas, vol. 1. Academic Press, Inc., New York.

4. Clyde, W. A., Jr. 1964. Mycoplasma species identification based upon growth inhibition by specific antisera. J. Immunol. 92:958-965.

5. Edward, D. G. ff. 1971. Determination of sterol requirement for Mycoplasmatales. J. Gen. Microbiol. 69:205-210.

6. Edward, D. G. ff., and W. A. Fitzgerald. 1951. Cholesterol in the growth of organisms of the pleuropneumonia group. J. Gen. Microbiol. 5:576-586.

7. Fabricant, J., and E. A. Freundt. 1967. Importance of extension and standardization of laboratory tests for the identification and classification of mycoplasma. Ann. N.Y. Acad. Sci. 143:50-58.

8. Fallon, R. J., and P. Whittlestone. 1969. Isolation, cultivation and maintenance of mycoplasmas, p. 211-267. In J. R. Norris and D. W. Ribbins (ed.), Methods in microbiology, vol. 3B. Academic Press, Inc., New York. 
9. Freundt, E. A., B. E. Andrews, H. Ernø, M. Kunze, and F. T. Black. 1973. The sensitivity of Mycoplasmatales to sodiumpolyanethol sulfonate and digitonin. Zentralbl. Bakteriol. Parasitenkd. Infectionskr. Hyg. Abt. 1 Orig. Reihe A 225:104-112.

10. Gross-Bellard, M. J., P. Oudét, and P. Chambon. 1973. Isolation of high molecular weight DNA from mammalian cells. Eur. J. Biochem. 36:32-38.

11. Hill, A. C. 1971. Mycoplasma caviae, a new species. J. Gen. Microbiol. 65:109-113.

12. Hill, A. C. 1971. The isolation of two further species of mycoplasma from guinea pigs. Vet. Rec. 83:225.

13. Hill, A. C. 1974. Mycoplasmas of small animal hosts, p. 311 316. In J. M. Bove and J. F. Duplan (ed.), Les Mycoplasmes/ Mycoplasmas, vol. 33. Institut National de la Sante et de la Recherche Medicale, Paris, France.

14. Hill, A. C. 1977 . The metabolic inhibition test for mycoplasmas based on phosphatase production. J. Hyg. 79:391-393.

15. Hill, A. C. 1984. Mycoplasma cavipharyngis, a new species isolated from the nasopharynx of guinea-pigs. J. Gen. Microbiol. 130:3183-3188.

16. Klieneberger-Nobel, E. 1962. Morphology of pleuropneumonialike organisms, p. 23-56. In E. Klieneberger-Nobel (ed.), Pleuropneumonia-like organisms (PPLO). Mycoplasmataceae. Academic Press, Inc., New York.

17. Leach, R. H. 1976. The inhibitory effect of arginine on growth of some mycoplasmas. J. Appl. Bacteriol. 41:259-264.

18. Manchee, R. J., and D. Taylor-Robinson. 1968. Hemadsorption and hemagglutination by mycoplasmas. J. Gen. Microbiol. 50:465-478.

19. Morton, H. E., and R. J. Roberts. 1967. Production of antimycoplasma (PPLO) antibodies in rabbits. Proc. Soc. Exp. Biol. Med. 125:538-543.

20. Mouches, C., and J. M. Bové. 1983. Electrophoretic characterization of mycoplasma proteins. Methods Mycoplasmol. 1:241255.

21. Polak-Vogelzang, A. A., R. Hagenaars, and S. Nagel. 1978. Evaluation of an indirect immunoperoxidase test for identification of Acholeplasma and Mycoplasma. J. Gen. Microbiol. 106:241-249.
22. Purcell, R. H., D. Taylor-Robinson, D. C. Wong, and R. M. Chanock. 1966. A color test for the measurement of antibody to the non-acid-forming human mycoplasma species. Am. J. Epidemiol. 84:51-66.

23. Purcell, R. H., D. Taylor-Robinson, D. C. Wong, and R. M. Chanock. 1966. Color test for the measurement of antibody to T-strain mycoplasmas. J. Bacteriol. 92:6-12.

24. Razin, S., and J. G. Tully. 1970. Cholesterol requirement of mycoplasmas. J. Bacteriol. 102:306-310.

25. Schildkraut, C. L., J. Marmur, and P. Doty. 1962. Determination of the base composition of deoxyribonucleic acid from its buoyant density in CsCl. J. Mol. Biol. 4:430-443.

26. Shepard, M. C., and D. R. Howard. 1970. Identification of "T" mycoplasmas in primary agar cultures by means of a direct test for urease. Ann. N.Y. Acad. Sci. 174:809-819.

27. Subcommittee on the Taxonomy of Mollicutes. 1979. Proposal of minimal standards for descriptions of new species of the class Mollicutes. Int. J. Syst. Bacteriol. 29:172-180.

28. Taylor-Robinson, D., R. H. Purcell, D. C. Wong, and R. M. Chanock. 1966. A colour test for the measurement of antibody to certain mycoplasma species based upon the inhibition of acid production. J. Hyg. 64:91-104.

29. Taylor-Robinson, D., M. H. Williams, and D. A. Haig. 1968. The isolation and comparative biological and physical characteristics of T-mycoplasmas of cattle. J. Gen. Microbiol. 54:33-46.

30. Timms, L. 1967. Isolation and identification of avian mycoplasmas. J. Med. Lab. Technol. 24:79-89.

31. Tully, J. G. 1965. Biochemical, morphological and serological characteristics of mycoplasma of murine origin. J. Infect. Dis. 115:171-185.

32. Tully, J. G., and S. Razin. 1969. Characteristics of a new sterol-nonrequiring Mycoplasma. J. Bacteriol. 98:970-978.

33. Venable, J. H., and R. Coggeshall. 1965. A simplified lead citrate stain for use in electron microscopy. J. Cell Biol. 25:407.

34. Williams, C. O., and R. G. Wittler. 1971. Hydrolysis of esculin and phosphatase production by members of the order $\mathrm{Myco}-$ plasmatales which do not require sterol. Int. J. Syst. Bacteriol. 21:73-77. 